\title{
Characterization of Selected Solar Radio Bursts Based on Solar Activity Detected by e- CALLISTO (Malaysia)
}

\author{
Z. S. Hamidi ${ }^{1, *}$, N. N. M. Shariff ${ }^{2}$, C. Monstein ${ }^{3}$ \\ ${ }^{1}$ School of Physics and Material Sciences, Faculty of Sciences, MARA University of Technology, \\ 40450, Shah Alam, Selangor, Malaysia \\ ${ }^{2}$ Academy of Contemporary Islamic Studies (ACIS), MARA University of Technology, \\ 40450, Shah Alam, Selangor, Malaysia \\ ${ }^{3}$ Institute of Astronomy, Wolfgang-Pauli-Strasse 27, Building HIT, Floor J, \\ $\mathrm{CH}-8093$ Zurich, Switzerland \\ *E-mail address: zetysh@salam.uitm.edu.my
}

\begin{abstract}
One of the main reasons to study more about the dynamics of solar radio bursts is because solar these bursts can interfere with the Global Positioning System (GPS) and communications systems. More importantly, these bursts are a key to understand the space weather condition. Recent work on the interpretation of the low frequency region of a main solar burst is discussed. Continuum radio bursts are often related to the solar activities such as an indication of the formation of sunspot, impulsive phase of solar flares and Coronal Mass Ejections (CMEs) and their frequencies correspond to the densities supposed to exist in the primary energy release volume. Specifically, solar burst in low frequency play an important role in interpretation of Sun activities. In this work, we have selected few solar bursts that successfully detected by our station at the National Space Centre, Banting Selangor. Our objective is to correlate the solar burst with Sun activities by looking at the main sources that responsibility with the trigger of solar burst. It is found that type II burst is dominant with Coronal Mass Ejections (CMEs), type III burst associated with solar flare, IV burst with the formation of active region and type $U$ burst high solar flare. We believed that this work is a good start to monitor Sun's activities in Malaysia as equatorial country.
\end{abstract}

Keywords: Sun; low frequency; solar radio; burst, type II; III;IV;V;U; e-CALLISTO

\section{INTRODUCTION}

The Sun is an active star that produces large-scale energetic events, such as solar flares and Coronal Mass Ejections (CMEs) which are observable across the electromagnetic spectrum, from gamma rays at hundreds of $\mathrm{MeV}$ to radio waves with wavelengths of tens of meters [1]. Solar radio bursts potentially describe possibilities of important phenomena in solar physics. The solar flare and Corona Mass Ejections (CMEs) are usually accompanied by solar radio bursts and the signals are usually can be characterized by background levels of radiation upon which are superimposed bursts. Variation of radio signal fading events caused by ionospheric absorption should be studied for clearer picture because maximum flares can produce streams of highly energetic particles a solar proton event which can impact the 
Earth's magnetosphere especially in the performance of radio-communication systems and strongly influences the local space weather in the vicinity of the Earth. Solar flare and Coronal Mass Ejections (CMEs) monitoring in radio region is very important in order to identify the active flares sources based on their nature and emission mechanisms and to relate their properties with plasma parameters in flaring regions [2]. It is an ideal indicator on investigating acceleration processes which are responsible for higher excited velocities. Besides, it also can be used as natural plasma probes traversing the corona and the interplanetary space, thus providing various space plasma parameters due to the various wave-particle and wave-wave interactions.

The dominant radio emission mechanism during impulsive flares depends on the wavelength observed and local conditions in the flaring source [3]. Coronal Mass Ejections (CMEs) are the most important manifestation of solar activity that drives the space weather near Earth [4,5]. In the meter wavelength range, 5 types of radio emissions are distinguished (review by [6] and at decimeter wavelengths there is a similar number [7] and [8]. It is well known that the radiations are caused coherently by electron beamed, shocks, possibly trapped electrons, and high-frequency waves in the plasma [9]. In this section, some main characteristics of each type will be explained. Type I solar burst is normally associated with storm burst in a very short period ( 1 to $20 \mathrm{~s}$ ) and potentially lasting from hours to days. This burst is considered as short-duration narrow band burst features that are associated with active regions [10]. Meanwhile, type II burst accompanying flares and lasting some minutes in which features drift gradually towards lower frequencies associated with CMEs. It is thought to be excited by magnetohydrodynamic (MHD) shockwaves associated with CMEs [11]. Only the CME driven shocks are expected to propagate into interplanetary space; the blast-waves are damped with distance and, probably, rarely escape the lower corona $[12,13]$. It is well known that there is a connection between some enhancements of solar radio waves and some solar flares. It seems probable that the first solar radio waves observed, but not recognized at the time as of solar origin, were of this class. One interesting fact about type III is it results from energetic particles escaping along open magnetic field lines [14]. This burst is a short-lived (a few seconds), broadband $(\approx 100 \mathrm{MHz})$ burst in which the frequency of maximum intensity drifts rapidly towards the lower frequencies due to solar flare event. It is now widely recognized that solar burst type IV always related to the development of sunspot groups and show broad continuum emission with rapidly-varying fine structures $[15,16]$. On the other hand, type V burst appearances a smooth short-lived continuum and formed after type III [17]. One of the main reasons to study more about the dynamics of solar radio bursts is because solar these bursts can interfere with GPS and communications systems [18]. More importantly, these bursts are a key to understand the space weather condition [19].

\section{CALLISTO SYSTEM CONFIGURATION EXPERIMENTAL SETUP}

The CALLISTO system consists of the Log Periodic Dipole Antenna (LPDA), preamplifier, and spectrometer, which operating from $45 \mathrm{MHz}$ to $870 \mathrm{MHz}$ [20]. The eCALLISTO network aims at $24 \mathrm{~h}$ coverage of the radio emission of the Sun [21]. It consist CALLISTO (Compound Astronomical Low-cost Low-frequency Instrument for Spectroscopy in Transportable Observatory) spectrometers, designed and built by electronics engineer Christian Monstein of the Institute for Astronomy of the Swiss Federal Institute of Technology Zurich (ETH Zurich), record the intensity of electromagnetic radiation at radio frequencies. The channel resolution is $62.5 \mathrm{kHz}$; while the radiometric bandwidth is about $300 \mathrm{KHz}$ with sampling time is exactly $1.25 \mathrm{~ms}$ per frequency-pixel. In principle, data that obtained from the CALLISTO can be transferred to a computer and saved locally via a R232 
cable in FIT files [22]. Current solar observatories, it provides a (wealth of data at high spectral, temporal, and spatial resolutions with the specification of the 0.25 second time resolution. All data are stored with a scale factor and an offset applied so that the measured ADC digits range fits into the byte data range $(0-255)$. The antenna has a boom length 5.45 meters with gain $7 \mathrm{dBi}$ [23]. Meanwhile, Low Noise Preamplifier is connected to maximize a gain more than $10 \mathrm{~dB}$ [24]. Within this range, it could be possible to detect solar activities specifically solar flare and Coronal Mass Ejections (CMEs). This system has been successfully installed at National Space Centre; Banting Selangor located $\left(3^{\circ} 5^{\prime} 00^{\prime \prime} \mathrm{N}\right.$ $101^{\circ} 32^{\prime} 00^{\prime \prime} \mathrm{E}$ ) [25]. Daily observations were performed for almost 12 hours [26]. Schematic diagram of the CALLISTO system is illustrated as in Figure 1.

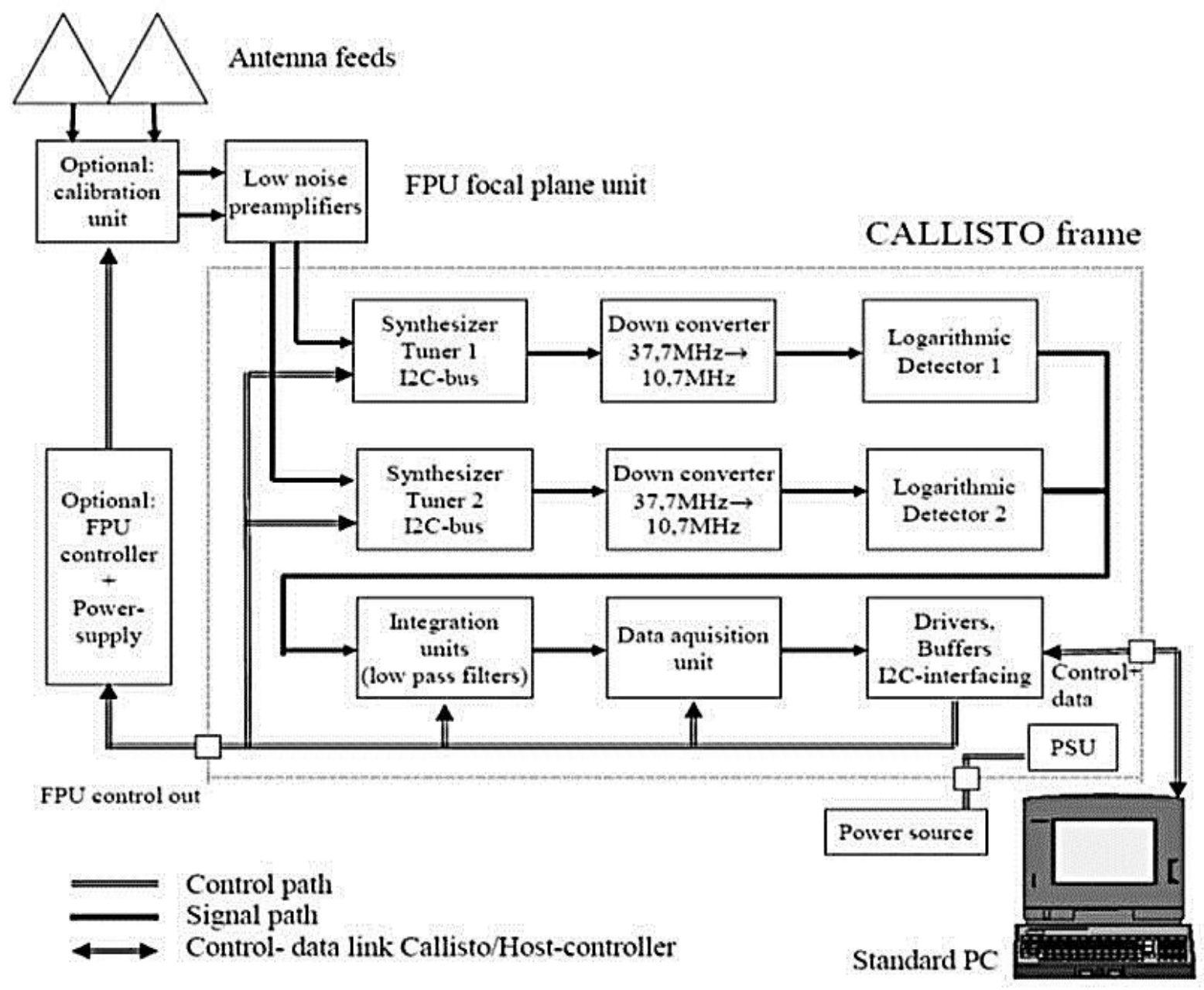

Figure 1. Schematic diagram of experimental setup of CALLISTO.

Up to date, the system which objective was designed to observe solar flares in 24 hours monitoring has been distributed to 19 sites. While in previous work we focused on the construction of the antenna and the system, now, we are looking at the behavior of each burst due to the data that successfully obtained from our site [27]. 
A part of calibration process, we have subtracted the pre-burst visibilities from the CALLISTO data in order to remove the signal from a quiet Sun. We also have checked the flux calibration by comparing the CALLISTO and relative amplitude of solar burst. In this work, we analyze the data obtained from our site using CALLISTO spectrometer. In this work, we have selected a few data that represent each burst. The significance of chosen the data will be explained in the next section [28-42].

\section{RESULTS AND DISCUSSION}

In order to provide an analytical description of each type of the burst, we listed the parameter that might influence the formations and the evolution of the burst such as sunspot number, radio flux and the active region that trigger the burst. We also focused on the specific range of frequency in order to observe the potential location that might need to be highlighted. This is very important because when there is expected any event of solar activities we are already targeting the range of frequencies.

For the spectra described in this paper, a complete wavelength was accomplished in 15 minutes. Due to constrain of the interference factors, the range of $150 \mathrm{MHz}$ till $400 \mathrm{MHz}$ had been chosen as selected data.

In this section, we present the results of several type bursts which can be detected successfully and related to solar events. Our current contribution to this effort is an observational study that begins to test the CALLISTO system. Detailed description of our own observations is given in Table 1 .

Table 1. Solar radio burst parameters.

\begin{tabular}{|c|c|c|c|c|}
\hline Type & II & III & IV & U \\
\hline Date & $\begin{array}{c}23 \text { rd October } \\
2012\end{array}$ & $\begin{array}{c}\text { 9th March } \\
2012\end{array}$ & $\begin{array}{c}5 \text { th March } \\
2012\end{array}$ & $\begin{array}{c}9 \text { th March } \\
2012\end{array}$ \\
\hline Time (UT) & $3: 17-3: 19$ & $4: 23-4: 26$ & $4: 14-4: 19$ & $\begin{array}{c}4: 12: 05- \\
4: 12: 06\end{array}$ \\
\hline $\begin{array}{c}\text { Range of frequency } \\
\text { (MHz) }\end{array}$ & $200-350$ & $150-400$ & $282-400$ & $311-383$ \\
\hline Active Region & 1598 & 1429 & 1429 & 1429 \\
\hline Sunspot number & 86 & 86 & 70 & 86 \\
\hline Radio flux (sfu) & 144 & 140 & 120 & 140 \\
\hline Event & $\begin{array}{c}\text { Coronal Mass } \\
\text { (CMections }\end{array}$ & $\begin{array}{c}\text { Solar Flare } \\
\text { type M 7.9 }\end{array}$ & $\begin{array}{c}\text { New active } \\
\text { region }\end{array}$ & $\begin{array}{c}\text { Solar Flare } \\
\text { type M7.9 }\end{array}$ \\
\hline Duration & 2 minutes & 3 minutes & 5 minutes & 1 minute \\
\hline
\end{tabular}

Coronal Mass Ejections (CMEs) will form type II bursts originated from the solar corona, expanding as they climb. Nevertheless, this burst of solar plasma being hurled from the eastern limb of the Sun is more like an explosion potentially release up to 100 billion $\mathrm{kg}$ of material with and the speed of the ejection exceeds $1000 \mathrm{~km} / \mathrm{second}$. Generally, the solar 
plasma is heated to tens of millions of degrees, protons and electrons, with nuclei are accelerated potentially closed to the speed of light.

In this case, the super-heated electrons from CMEs move along the magnetic field lines faster than the solar wind can flow. As a consequence, rearrangement of the magnetic field and solar flares possibly will result in the configuration of a shock that accelerates particles ahead of the CME loop. The observation of solar radio burst during CMEs requires high resolution in frequency. For this event, we considered a time window over 3 hours (360 minutes) covering the phases of impulsive courses (waveforms) and background signals. Figure 2 shows the solar radio burst type II on $23^{\text {rd }}$ October 2012.

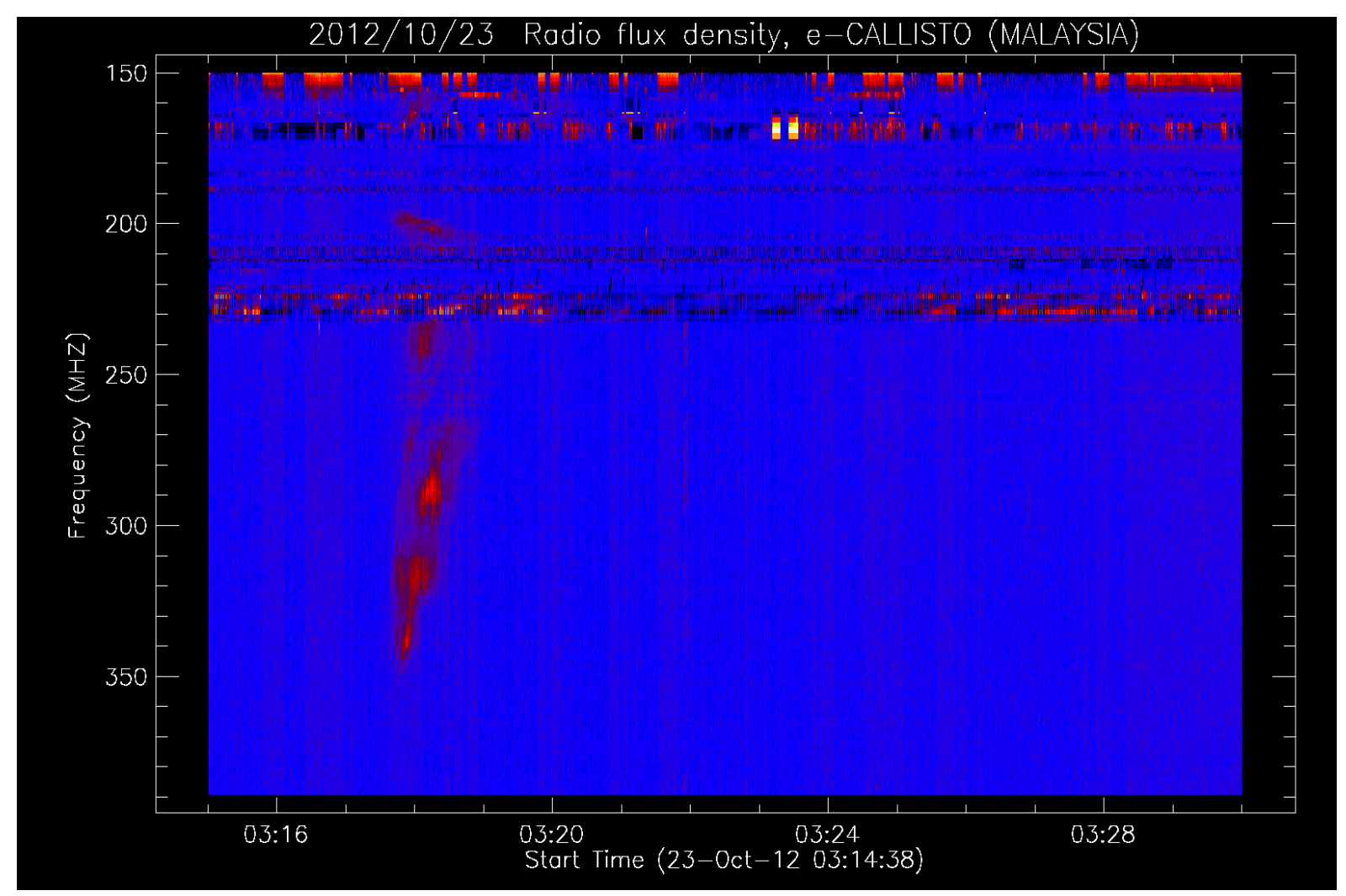

Figure 2. Solar radio burst type II on 23rd October 2012.

The type III solar radio bursts, which are generated when high-energy electrons are ejected from the Sun, are characterized by a rapid drift in frequency from hundreds of megahertz to tens of $\mathrm{kHz}$. It is believed that the process of producing type III solar radio bursts is associated with the excitation of Langmuir waves, which are oscillations in the electron density in a plasma, followed by the conversion of these waves into radio emissions. During solar flares there may be large increases (bursts) in radio emission lasting anywhere from a few seconds to several hours.

In order to understand the possible mechanism of dynamical structure of the burst, we have investigated relationships and time integrations of the bursts with soft/hard as well as solar flares. It is clearly seen an impulsive lace burst were detected at 4:24 UT and it is more plausible that the energies are confined to the top of the loop and it is confined with an X-ray results. The burst is now at the end of the phase where we can observe it is now decreased till 4:52 UT. Figure 3 illustrate the solar radio burst type III with a high energetic particles. 


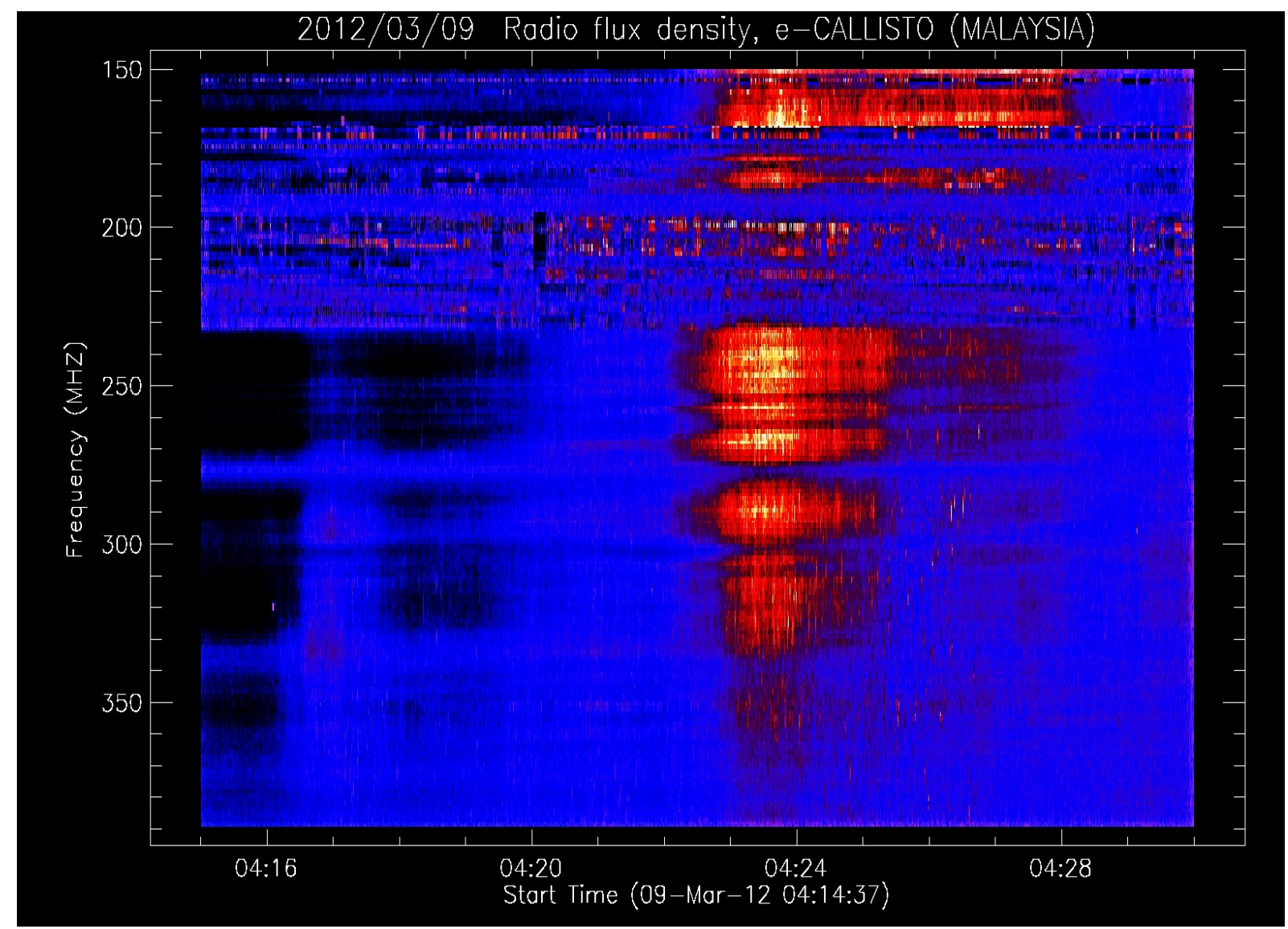

Figure 3. Solar radio burst type III on $12^{\text {th }}$ March 2012

Solar burst type IV always related to the development of sunspot groups. This first light curve associated with a class M 2.0 solar flare on 5th March 2012 also successfully detected at the National Space Centre, Banting. Here we consider the range that almost free from interference from $240 \mathrm{MHz}$ till $380 \mathrm{MHz}$, see Figure 4. Time variations in the emission may due to the changes in the electron density. However, these variations mainly proceed slowly and due to the change in the local ionization temperatures.

During $9^{\text {th }}$ March 2012, a strong M 7.9 class of solar flare was recorded from solar Active Region AR1429. It is clearly seen an inverted type U burst occurs between $310 \mathrm{MHz}$ till $384 \mathrm{MHz}$ within 1 minute. In this event, an M6 solar flare occurred in the active region AR 1429 starting at 3:32 UT and ending at 05:00 UT, with the peak at 4:12 UT. If one looks very closely, before type $U$ burst form, there is a group of ten of solar burst types III occurred from 4:06-4:10 UT. 


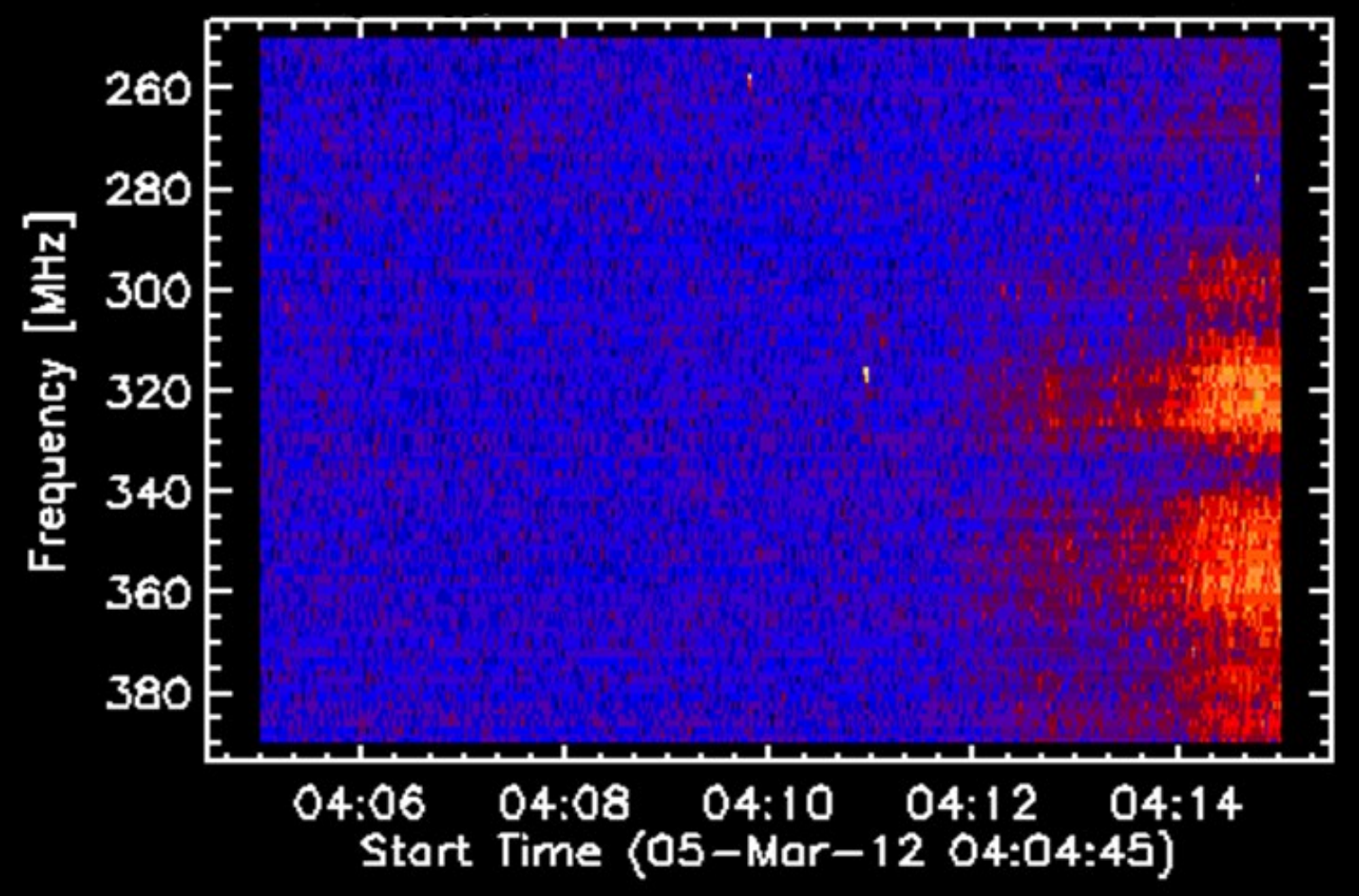

Figure 4. Solar radio burst type IV on $5^{\text {th }}$ March 2012.

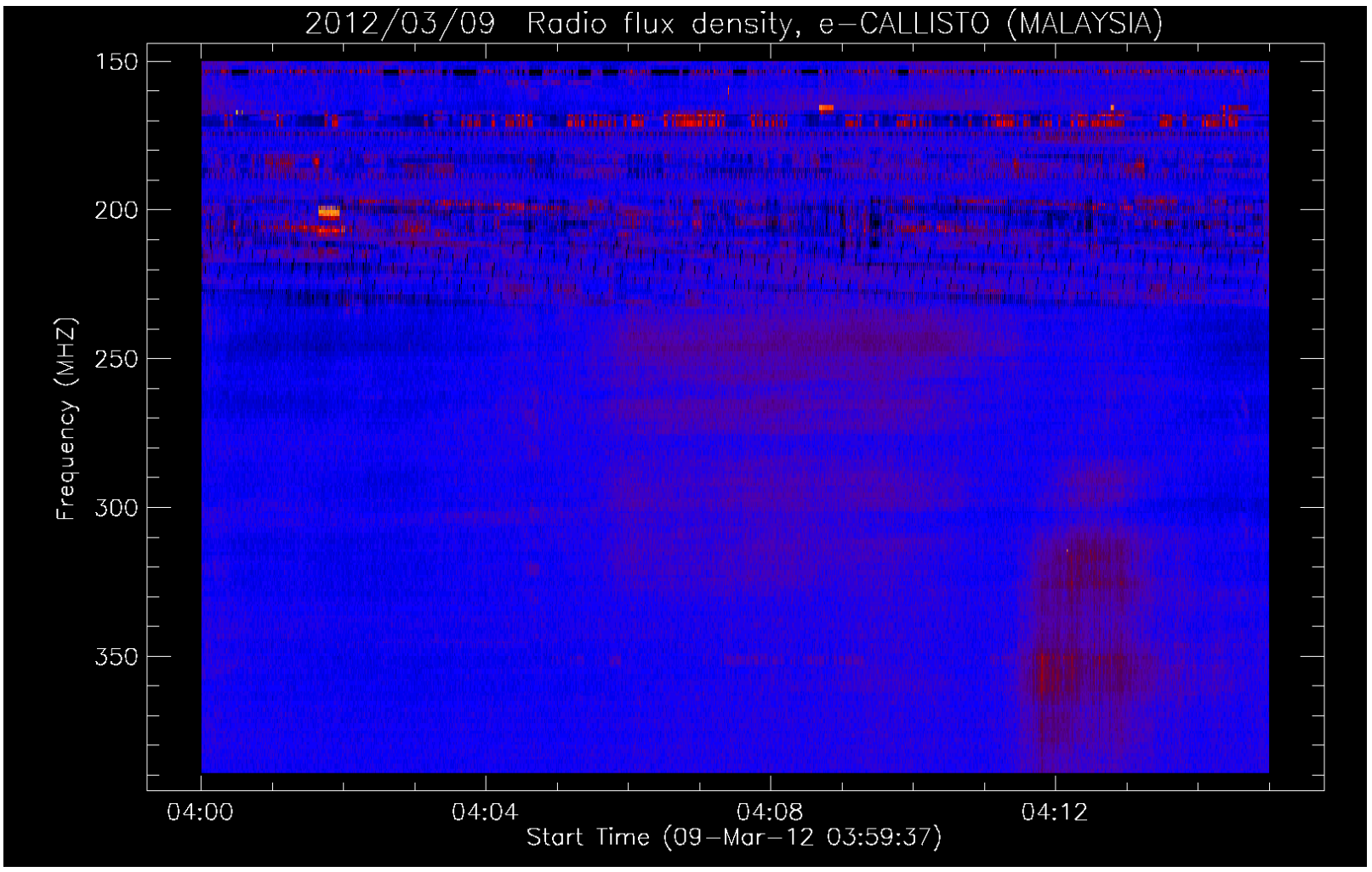

Figure 5. Solar radio burst type U on $9^{\text {th }}$ March 2012. 
During $9^{\text {th }}$ March 2012, a strong M 7.9 class of solar flare was recorded from solar Active Region AR1429. It is clearly seen an inverted type U burst occurs between $310 \mathrm{MHz}$ till $384 \mathrm{MHz}$ within 1 minute. In this event, an M6 solar flare occurred in the active region AR 1429 starting at 3:32 UT and ending at 05:00 UT, with the peak at 4:12 UT. If one looks very closely, before type $U$ burst form, there is a group of ten of solar burst types III occurred from 4:06-4:10 UT.

\section{CONCLUSIONS}

There is a growing interest in observing solar burst in low frequency of the radio region due to the increasing number of solar activities towards $24^{\text {th }}$ solar cycle. In this article, a comprehensive analysis of variation of solar burst has been presented. There is a growing interest in observing solar burst in low frequency of radio region. It could not be doubted that e-CALLISTO network plays a dominant and important database on the target monitoring solar activities in 24 hours. The results presented in this paper point to the importance of observing Sun activities in radio region. Still our data show hints of possible solar activities that can be detected in this lower region. Our radio observations were carried out simultaneously with the CALLISTO spectrometer is could contribute a good data due to our advantages, which made daily observation for 12 hours throughout the years and the different perspective seems our location as an equotarial site. This factor may be important for observation of burst with long duration. It is hoped that we could possible to gain a better data that can be used as a reference.

\section{ACKNOWLEDGEMENT}

We are grateful to the LASCO,SDO/AIA, NOAA and SWPC make their data available online. This work was partially supported by the FRGS (600 RMI/FRGS 5/3 2012) UiTM grants. Special thanks to C. Monstein from ETH Zurich, Switzerland who set up and gives us training on analyzing the data. Also to National Space Agency and National Space Centre for giving us a site to set up this project and support this project. Solar burst monitoring is a project of cooperation between the Institute of Astronomy, ETH Zurich, and FHNW Windisch, Switzerland, MARA University of Technology and University of Malaya. This paper also used NOAA Space Weather Prediction Centre (SWPC) for the sunspot, radio flux and solar flare data for comparison purpose. The research has made use of the National Space Centre Facility and a part of an initiative of the International Space Weather Initiative (ISWI) program.

\section{BIOGRAPHY}

Dr Zety Sharizat Hamidi is currently a lecturer and focused in Solar Astrophysics research specifically in radio astrophysics at the School of Physics and Material Sciences, Faculty of Sciences, MARA University of Technology, 40450, Shah Alam, Selangor, Malaysia. Involve a project under the International Space Weather Initiative (ISWI).

C. Monstein is a senior Engineer at Institute of Astronomy, Wolfgang-Pauli-Strasse 27, Building HIT, Floor J, CH-8093 Zurich, Switzerland and one of the researchers who initiated the CALLISTO system around the world.

Dr Nur Nafhatun Md Shariff is a senior lecturer in Academy of Contemporary Islamic Studies (ACIS), MARA University of Technology, 40450, Shah Alam, Selangor, Malaysia.Her current research is more on sustainability; environmental aspect. She is looking forward for cross-field research, i.e. solar astrophysics, light pollution measurement (mapping) and religious studies. 


\section{References}

[1] E.P.C. P. Zucca, J. McCauley, P.T. Gallagher, C. Monstein, R. T. J. McAteer, Solar Physics 1007 (2012).

[2] Z.S. Hamidi, Z. Abidin, Z. Ibrahim, N. Shariff, C. Monstein, Observations of coronal mass ejections (CMEs) at low frequency radio region on 15th April 2012, in: R.Shukor (Ed.), PERFIK 2012, American Institute of Physics, Malaysia, 2013, pp. 5.

[3] Z. Hamidi, N. Shariff, C. Monstein, Z. Ibrahim, International Letters of Chemistry, Physics and Astronomy 7 (2014) 37-44.

[4] J.T. Gosling, J. Geophys. Rev. 98 (1993).

[5] J.T. Gosling, J. Geophys. Rev. 99 (1994).

[6] D.J.L. McLean, N. R, Solar Radiophysics, Cambridge: Cambridge University Press., 1985.

[7] M.B. Güdel, Astr. Astrophys. 75 (1988).

[8] H.B. Isliker, Astr. Astrophys. Sup. 104 (1994).

[9] C.M.a.H.M. Arnold O. Benz, CALLISTO - A New Concept for Solar Radio Spectrometers Kluwer Academic Publishers, 2004.

[10] D.B. Melrose, Solar Physics 43 (1975) 211-236.

[11] G.J. Nelson, Melrose, D.B., Solar radiophysics: Studies of emission from the sun at metre wavelengths, in: D.J.L. McLean, N. R. (Ed.), Cambridge Univ. Press, Cambridge, 1985.

[12] N. Gopalswamy, AGU Geophysical Monograph Series 165 (2006).

[13] M. Pick, Forbes T.G., Mann Space Sci. Revs 123 (2006).

[14] Z.S. Hamidi, N. Anim, N.N.M. Shariff, Z.Z. Abidin, Z.A. Ibrahim, C. Monstein, Dynamical structure of solar radio burst type III as evidence of energy of solar flares, in: R.Shukor (Ed.), PERFIK 2012, American Institute of Physics, Malaysia, 2013, pp. 11-15.

[15] D.J. McLean, Labrum N.R., Solar radiophysics: Studies of emission from the sun at metre wavelengths., 1985.

[16] Z.S. Hamidi, N.N.M. Shariff, F.N.Z. Ulum, Z.Z. Abidin, Z.A. Ibrahim, International Journal of Astronomy 5 (2012) 101-106.

[17] Z. Hamidi, Z. Abidin, Z. Ibrahim, C. Monstein, N. Shariff, International Journal of Fundamental Physical Science 2 (2012) 3.

[18] Z.S. Hamidi, Z.Z. Abidin, Z.A. Ibrahim, N.N.M. Shariff, U.F.S.U. Ibrahim, R. Umar, Preliminary analysis of investigation Radio Frequency Interference (RFI) profile analysis at Universiti Teknologi MARA, IEEE, 2011, pp. 311-313.

[19] Z. Hamidi, N. Shariff, Z. Abidin, Z. Ibrahim, C. Monstein, Malaysian Journal of Science and Technology Studies 9 (2013) 15-22.

[20] Z.S. Hamidi, N.M. Anim, N. N.S. Hakimi, N. Hamzan, A. Mokhtar, N.Syukri, S. Rohizat, I. Sukma, Z.A. Ibrahim, Z.Z. Abidin, N.N.M. Shariff, C. Monstein, International Journal of Fundamental Physical Sciences 2 (2012) 4. 
[21] C.M. A. O. Benz, H. Meyer, P. K. Manoharan „A.A. R. Ramesh , A. Lara, J. Paez , K.-S. Cho, A World-Wide Net of Solar Radio Spectrometers: e-CALLISTO Earth Moon Planet 1007 (2009).

[22] Z. Hamidi, Z. Abidin, Z. Ibrahim, N. Shariff, C. Monstein, International Journal of Engineering Research and Development 3 (2012) 36-39.

[23] Z.S. Hamidi, Z. Abidin, Z. Ibrahim, C. Monstein, N. Shariff, International Journal of Fundamental Physical Sciences 2 (2012) 32-34.

[24] Z.S. Hamidi, Z.Z. Abidin, Z.A. Ibrahim, N.N.M. Shariff, Indication of radio frequency interference (RFI) sources for solar burst monitoring in Malaysia, AIP Conference Proceedings 1454 (2012) 43.

[25] Z.S. Hamidi, N.N.M. Shariff, Evaluation of Signal to Noise Ratio (SNR) of Log Periodic Dipole Antenna (LPDA) Business Engineering and Industrial Applications Colloquium 2013, IEEE, Langkawi, Malaysia, 2013, pp. 434-438.

[26] Z.S. Hamidi, N. Shariff, Z. Abidin, Z. Ibrahim, C. Monstein, Middle-East Journal of Scientific Research 12 (2012) 6.

[27] Z.S. Hamidi, Z. Abidin, Z. Ibrahim, N. Shariff, Indication of radio frequency interference (RFI) sources for solar burst monitoring in Malaysia, ICPAP 2011, AIP Publisher, Indonesia, 2012, pp. 6.

[28] Z. S. Hamidi, N. N. M. Shariff, C. Monstein, International Letters of Chemistry, Physics and Astronomy 13(1) (2014) 77-87.

[29] Z. S. Hamidi, N. N. M. Shariff, International Letters of Chemistry, Physics and Astronomy 4 (2014) 29-36.

[30] Z. S. Hamidi, N. N. M. Shariff, International Letters of Chemistry, Physics and Astronomy 5 (2014) 32-42.

[31] Z. S. Hamidi, N. N. M. Shariff, International Letters of Chemistry, Physics and Astronomy 5 (2014) 43-49.

[32] Z. S. Hamidi, N. N. M. Shariff, International Letters of Chemistry, Physics and Astronomy 7 (2014) 21-29.

[33] Z. S. Hamidi, N. N. M. Shariff, International Letters of Chemistry, Physics and Astronomy 7 (2014) 30-36.

[34] Z. S. Hamidi, N. N. M. Shariff, C. Monstein, W. N. A. Wan Zulkifli, M. B. Ibrahim, N. S. Arifin, N. A. Amran, International Letters of Chemistry, Physics and Astronomy 8 (2014) 13-19.

[35] Z. S. Hamidi, N. N. M. Shariff, C. Monstein, W. N. A. Wan Zulkifli, M. B. Ibrahim, N. S. Arifin, N. A. Amran, International Letters of Chemistry, Physics and Astronomy 9 (2014) 8-15.

[36] Z. S. Hamidi, N. N. M. Shariff, M. F. Ali, C. Monstein, W. N. A. Wan Zulkifli, M. B. Ibrahim, N. S. Arifin, N. A. Amran, International Letters of Chemistry, Physics and Astronomy 9 (2014) 84-92. 
[37] Z. S. Hamidi, N. N. M. Shariff, C. Monstein, International Letters of Chemistry, Physics and Astronomy 11(1) (2014) 51-58.

[38] Z. S. Hamidi, N. N. M. Shariff, C. Monstein, International Letters of Chemistry, Physics and Astronomy 11(2) (2014) 135-145.

[39] Z. S. Hamidi, N. N. M. Shariff, C. Monstein, International Letters of Chemistry, Physics and Astronomy 11(2) (2014) 167-176.

[40] Z. S. Hamidi, C. Monstein, N. N. M. Shariff, International Letters of Chemistry, Physics and Astronomy 11(3) (2014) 243-256.

[41] Z. Hamidi, N. Shariff, C. Monstein, International Letters of Chemistry, Physics and Astronomy 10 (2014) 81-90.

[42] Z. Hamidi, N. Shariff, C. Monstein, International Letters of Chemistry, Physics and Astronomy 12 (2014) 84-102. 